\title{
Study of Four Onion Varieties Drying Kinetics in an Oven and a Solar Greenhouse
}

\author{
Ngoné Fall Beye ${ }^{1,2}$, Nicolas Cyrille Ayessou ${ }^{1}$, Cheikhou Kane ${ }^{1}$, Mariame Niang Mbaye ${ }^{1}$, Cheikh Talla ${ }^{3}$, Abdou \\ Sene $^{2} \&$ Codou Mar Diop ${ }^{1}$ \\ ${ }^{1}$ Polytechnic School, (ESP) / Center for Food Security and Functional Molecules Studies (CESAM-RESCIF), \\ Cheikh Anta Diop University, Dakar, Senegal \\ ${ }^{2}$ Laboratory for Biological Sciences, Agronomy and Complex Systems Modeling (LaBAM) / UGB, Saint-Louis, \\ Senegal \\ ${ }^{3}$ Pasteur Institute of Dakar, Epidemiology Unit for Infectious Diseases - 36, Avenue Pasteur, Dakar, Senegal \\ Correspondence: Ngoné Fall Beye, Training and Research Unit of Agricultural Sciences, Aquaculture and Food \\ Technologies (UFR S2ATA), Department of Food Technologies, Gaston Berger University, Senegal. Tel: \\ 221-339-601-986. E-mail: ngone-fall.beye@ugb.edu.sn / fallbeye@ gmail.com
}

\author{
Received: March 4, 2019 Accepted: March 22, 2019 Online Published: April 15, 2019 \\ doi:10.5539/jfr.v8n3p59 URL: https://doi.org/10.5539/jfr.v8n3p59
}

\begin{abstract}
Onion production (Allium cepa L.) in Senegal reached 390000 tons in 2016. Due to post-harvest losses, annual demand (150 000 and 250000 tons) is being met through imports. This work consists in proposing a drying process at a lower cost to overcome this dependence and preserve the quality of the product. The optimization of local onion varieties drying in an oven and in solar greenhouse, as well as the physicochemical characterization of the products were carried out. The moisture of fresh onion bulb varies between $85.56 \pm 0.60$ and $89.13 \pm 0.69$ $(\%)$. To obtain a moisture $\leq 8.89 \pm 0.16(\%)$ ensuring stability, the optimal drying conditions in the oven are $60^{\circ}$ $\mathrm{C} / 6 \mathrm{H}$ (Galmi Violet) and 7H (Safari, Gandiol F1 and Orient F1). Under these conditions, the content of polyphenols in g equivalent of gallic acid / $100 \mathrm{~g} \mathrm{db}$ increases $(0.111 \pm 0.0040$ to $0.312 \pm 0.0041$ before drying, $0.546 \mathrm{~g} \pm 0.0117$ to $0.837 \pm 0.0091$ after drying). Optimum solar drying in a greenhouse is obtained between temperatures of 35 to $65^{\circ} \mathrm{C} / 8 \mathrm{H}-9 \mathrm{H}$. From a perspective of sustainable development, the perspective is the modeling of drying kinetics in a solar greenhouse.
\end{abstract}

Keywords: Allium cepa L., Local varieties, drying, optimal conditions, moisture, water activity, polyphenols

\section{Introduction}

Senegalese agriculture, particularly rainy and seasonal agriculture, contributed about $18 \%$ of GDP in 2015 (National Agency for Statistics and Demography [ANSD]) and is one of the key levers for ensuring food security. Horticultural is the most dynamic sub-sector of this Senegalese agriculture, with a growth of between $5 \%$ and 10\% since 2004.(ANSD, 2014; Direction de l'Horticulture [DH], 2015). This performance is mainly driven by the growth of the onion sub-sector which represents $60 \%$ of horticultural production (DH, 2016).

In fact, onion (Allium cepa L.), a very popular vegetable in Senegal, with an annual consumption of between 150,000 and 250,000 tons (ARM, 2016) represents 25\% of household expenditure. The most common use of onion in households across the country is fragmenting the bulb into pieces that are incorporated into recipes for flavor development. However, despite a record production of 390,000 tons in 2016, meeting household demand over the year remains dependent on imports due to significant post-harvest losses due to the high moisture content of the onion. Thus, to reduce post-harvest losses, developing the dehydration process seems to be an excellent opportunity but the process requires a lot of energy.

Many studies on food products drying have shown that drying efficiency and kinetic characteristics depend on the drying conditions and the types of products (varieties and their degree of maturity, shape, thickness, composition), but also on the electric or solar drying mode. Among these studies can be mentioned those on the onion (Ahmed-Zaid, 1999; Albitar, Mounir, Besombes, \& Allaf, 2011; Anwar \& Tiwari, 2001; Kiranoudis, Maroulis, \& Marinos-Kouris, 1992; Krokida, Karathanos, Maroulis, \& Marinos-Kouris, 2003; Sarsavadia, Sawhney, Pangavhane, \& Singh, 1999), the pepper (Anwar \& Tiwari, 2001; Lhendup, 2005) and the beef 
(Lhendup, 2005; Tom, 2015).

On the other hand, the use of solar drying, a major lever to overcome the energy constraint, preserves the quality of products despite the variability of climatic conditions (Boughali, 2010; Jannot, 2006; Mendez Lagunas, 2007).

These findings and the absence of data in the literature on local varieties justify the initiation of this research.

The objective of this study is to optimize the drying of four onion varieties in an oven and in solar greenhouse and to compare solar drying, which reduces the energy bill, to electric convective drying. Optimal drying conditions are determined by studying the impact of this process on some major biochemical and physicochemical parameters.

\section{Materials and Methods}

\subsection{Materials}

\subsubsection{Plant Material}

The local onion is collected in the cooperative of the locality of RAO in Saint-Louis (Senegal). The varieties studied are Galmi violet, Safari, Gandiol F1 (Gandiolais) and Orient F1 (Orient) with a maturity of 85\% of leaves falling at harvest.

\subsubsection{Analysis Equipment}

Analysis equipment: an oven with ventilation (Memmert brand), a solar greenhouse equipped with a ventilation system to regulate the ambient air temperature and humidity, sensors for temperature and humidity readings, capsules in pyrex, drying racks, a scale (Denver instrument brand with a reliability rate of $0.0001 \mathrm{~g}$ ), a thermohygrometer (Voltcraft brand with a precision of $1{ }^{\circ} \mathrm{C}$ and $3.5 \%$ ), a water activity meter (Rotronic HP 23 brand), a pH meter (HI 23 brand), a burette, a spectrophotometer (Specord brand), a mineralizer, a distiller and laboratory glassware.

\subsubsection{Graphical and Statistical Representation Tools}

Data exploitation is carried out with both the R version 3.4.0 (Team R Core, 2017) software for the comparison test between the two methods of drying, the analysis of variance and the concordance of the measurements, and the Excel version 2016 software as a tool for scientific calculations for graphic representations.

\subsection{Methods}

The peeled onions are washed in chlorinated water $100 \mathrm{ppm}(0.1 \mathrm{mg} / \mathrm{L}$ water), rinsed three times with clean water, dewatered and finely chopped with a chopper to neglect the deformation of the product during the drying process.

The thickness of the samples is in the range of $1.7 \mathrm{~mm}$.

\subsubsection{Kinetics Study}

The tests are conducted in an oven in the temperature range of $50^{\circ} \mathrm{C}$ to $70^{\circ} \mathrm{C}$ with a step of $5^{\circ} \mathrm{C}$ to determine the optimum temperature / time to obtain stable products.

Ten grams are taken from the chopped onions of three different bulbs, and spread in pyrex cups. The experiments are carried out with ventilation at a fixed air velocity of $2.4 \mathrm{~m} / \mathrm{s}$ and a relative humidity between 10 and $15 \%$ (Babalis \& Belessiotis, 2004; Clemente, Frías, Sanjuan, Benedito, \& Mulet, 2011; Kiranoudis et al., 1992; Krokida et al., 2003; Sarsavadia et al., 1999). 


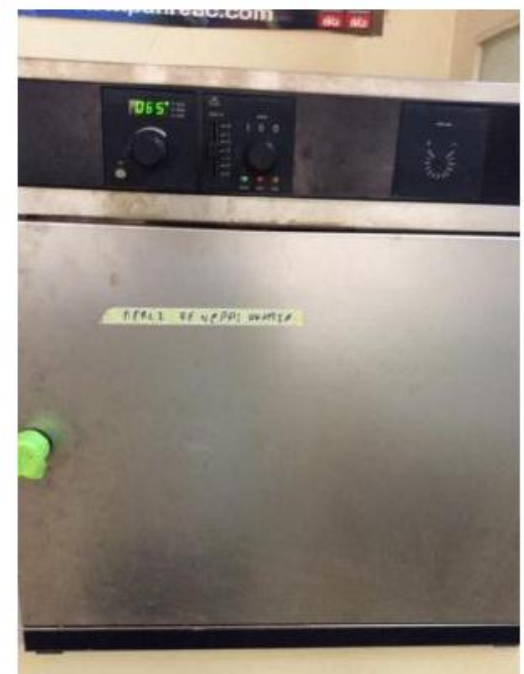

(a)

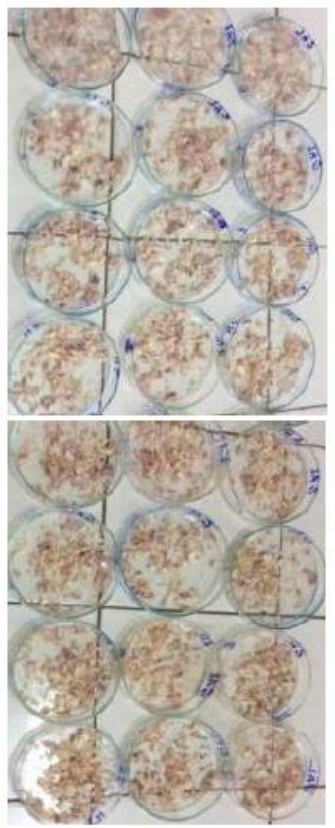

(b)

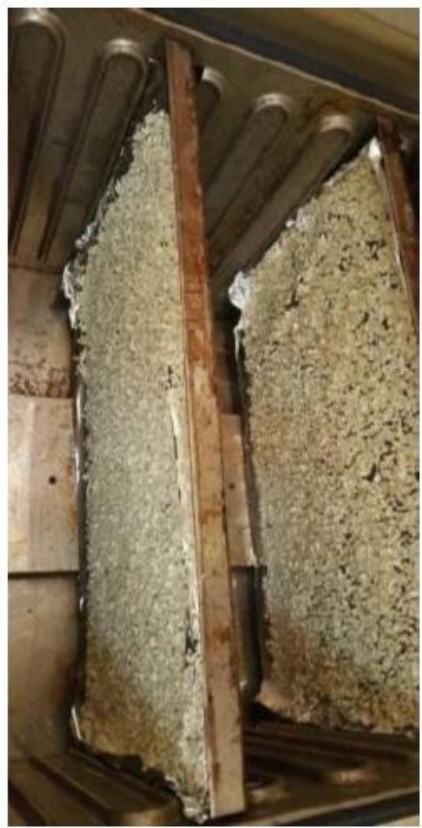

(c)

Figure 1. (a) Photo of the oven (b) cups for monitoring kinetics (c) trays for producing onion powder samples

Regarding solar greenhouse drying, the four varieties are dried simultaneously (one variety per drying rack). Each rack is squared in four parts of equal size $(0.74 \mathrm{X} 0.71 \mathrm{~m})$ on which three $\mathrm{kg}$ of onion are spread in monolayer. Inside the solar greenhouse, removable room sensors make it possible to follow the evolution of the temperature and the relative humidity, two determining parameters for the drying. During solar greenhouse drying, the relative humidity varies between $10-60 \%$ and the temperature varies between $35^{\circ} \mathrm{C}$ and $65^{\circ} \mathrm{C}$.

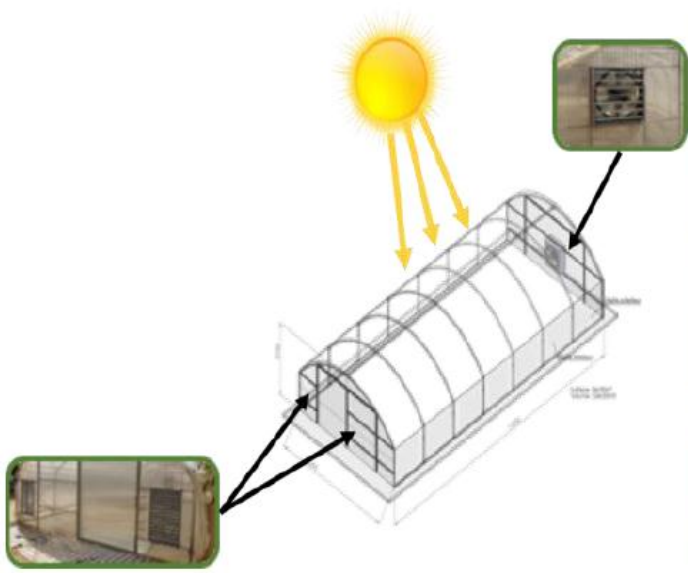

(a)

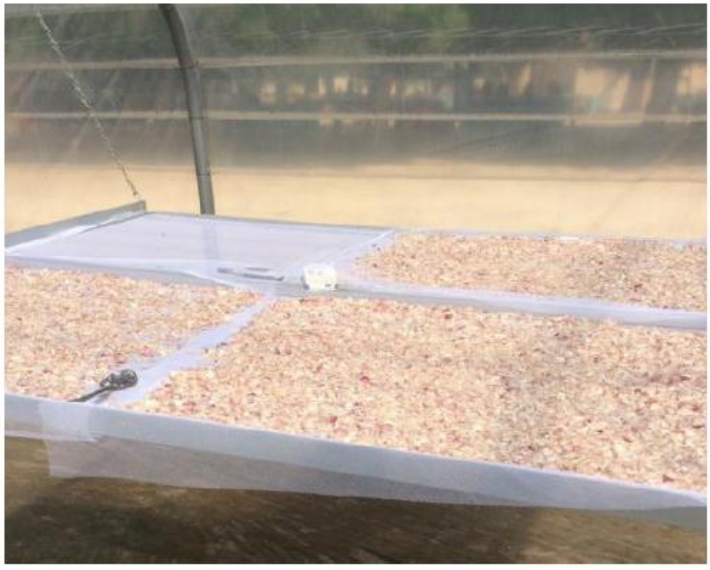

(b)

Figure 2. (a) Photo of the solar greenhouse from the outside with the ventilation and air extraction system and (b) photo of a drying rack with the onions distributed in a thin layer

Both in the oven and in the solar greenhouse, the experiments are performed in triplicate and the monitoring of the weight loss takes place every hour.

\subsubsection{Physico-Chemical Analyses}

The various biochemical and physicochemical analyses performed on raw materials as well as onion powders obtained by dehydration in an oven and in a solar greenhouse are the $\mathrm{pH}$ according to NF V76-122: 1994, NF 
EN 1132, titratable acidity according to NF V 05-101 January 1974, European Standard EN 12147 December 1996), the moisture content with reference to standard NF ISO 712: 2009), the activity of water according to standard NF EN ISO 17025). In addition, the polyphenols, the most important functional elements to be preserved during the drying of the four onion varieties, are evaluated by the Folin-Ciocalteu reagent spectrophotometric assay method in a basic medium at $760 \mathrm{~nm}$. The total polyphenol content is expressed in gallic acid equivalent.

All moisture measurements and characterization analyses are performed in triplicate to ensure repeatability.

\subsubsection{Statistical Analyses}

The evaluation of the reproducibility and the repeatability of the measurements is made by the numerical method which is the LIN coefficient (Lawrence \& Lin, 1989).

The Lin's concordance coefficient varies between -1 and 1 , where the values $-1,0$ and +1 respectively mean perfect discordance, zero concordance and perfect match.

The Student's parametric test is used for the comparison of the:

$>$ characteristics of onion varieties (water activity, titratable acidity, $\mathrm{pH}$ and polyphenol content) before drying;

$>$ stability moisture of the oven-dried samples and those dried in a solar greenhouse.

All statistical analyses are performed with a significant threshold of $\mathrm{p}<0.05$.

\section{Results and Discussion}

\subsection{Characteristics of Onion Varieties before Drying}

The physical and chemical characteristics of the samples before drying are presented in table 1.

All varieties are marked by a high moisture content and $\mathrm{Aw}, \mathrm{pH}$ and polyphenols values are almost identical. Only the acidity of the Safari variety seems to stand out $(9.23 \mathrm{mEq} / 100 \mathrm{~g} \mathrm{db})$ from that of the other varieties (between 4 and $6 \mathrm{mEq} / 100 \mathrm{~g} \mathrm{db}$ ).

The two most important criteria for the stability of food products, namely the moisture content (\%) and the water activity of fresh onions are respectively for:

$>$ Galmi violet $85.56 \pm 0.60 / 0.945 \pm 0.01$;

$>$ Safari $88.11 \pm 0.61 / 0.950 \pm 0.001$

$>$ Gandiol F1 $86.99 \pm 0.10 / 0.940 \pm 0.001$;

$>$ Orient F1 $89.13 \pm 0.69 / 0.947 \pm 0.009$.

Table 1. Major characteristics of onion samples before drying

\begin{tabular}{lllll}
\hline \multicolumn{1}{c}{ Variety } & \multicolumn{1}{c}{ Galmi Violet } & \multicolumn{1}{c}{ Safari } & \multicolumn{1}{c}{ Gandiol F1 } & \multicolumn{1}{c}{ Orient F1 } \\
\hline Moisture (\%wb) & $85.56 \pm 0.60$ & $88.11 \pm 0.61$ & $86.99 \pm 0.10$ & $89.13 \pm 0.69$ \\
\hline Water Activity & $0.945 \pm 0.011$ & $0.950 \pm 0.001$ & $0.940 \pm 0.013$ & $0.947 \pm 0.009$ \\
\hline Polyphenols (g EAG /100g db) & $0.111 \pm 0.0040$ & $0.134 \pm 0.0065$ & $0.162 \pm 0.0016$ & $0.312 \pm 0.0041$ \\
\hline Titrable Acidity (mEq / 100g db) & $6.12 \pm 0.00$ & $9.23 \pm 0.00$ & $4.51 \pm 0.02$ & $6.13 \pm 0.38$ \\
\hline pH at 10\% & $6.42 \pm 0.03$ & $6.29 \pm 0.06$ & $6.35 \pm 0.03$ & $6.37 \pm 0.03$ \\
\hline
\end{tabular}

Legend: Equivalent Gallic Acid (EAG)

\subsection{Optimal Drying Conditions}

The Lin coefficients obtained for the measurement concordance test for all oven drying and solar greenhouse drying kinetics vary between 0.9993555 and 0.9999317 with a confidence interval of [0.9991869; 0,9999431]. This indicates that there is a perfect match between the three measurements made for each test.

The results of the statistical test for the comparison of the oven drying kinetic data to that in solar greenhouse are between [-0.44906 - 0.73362] for Student's parameter $(t)$, [0.4697 - 0.9572] for the pvalue and [24 - 26] for the degree of freedom (df). Therefore, regardless of the oven drying temperature, $p>5 \%$ values show that there is no significant difference between oven drying and solar greenhouse drying kinetics.

The stability of dried fruits and vegetables is guaranteed with a moisture content of $8 \pm 2 \%$ or less and an Aw between 0.5 and 0.6 to avoid any microbial activity (Bernard \& Carlier, 1992; ESA, 2004; Faiveley, 2003; Le Meste \& Chiotelli, 2002). These values serve as a reference to determine the optimal drying conditions taking 
into account the evolution of the physicochemical characteristics after drying.

\subsubsection{Optimal Drying Conditions in the Oven}

Figure 3 shows the evolution of the moisture content of Galmi Violet, Safari, Gandiol F1 and Orient F1 varieties dried in an oven at different temperatures.
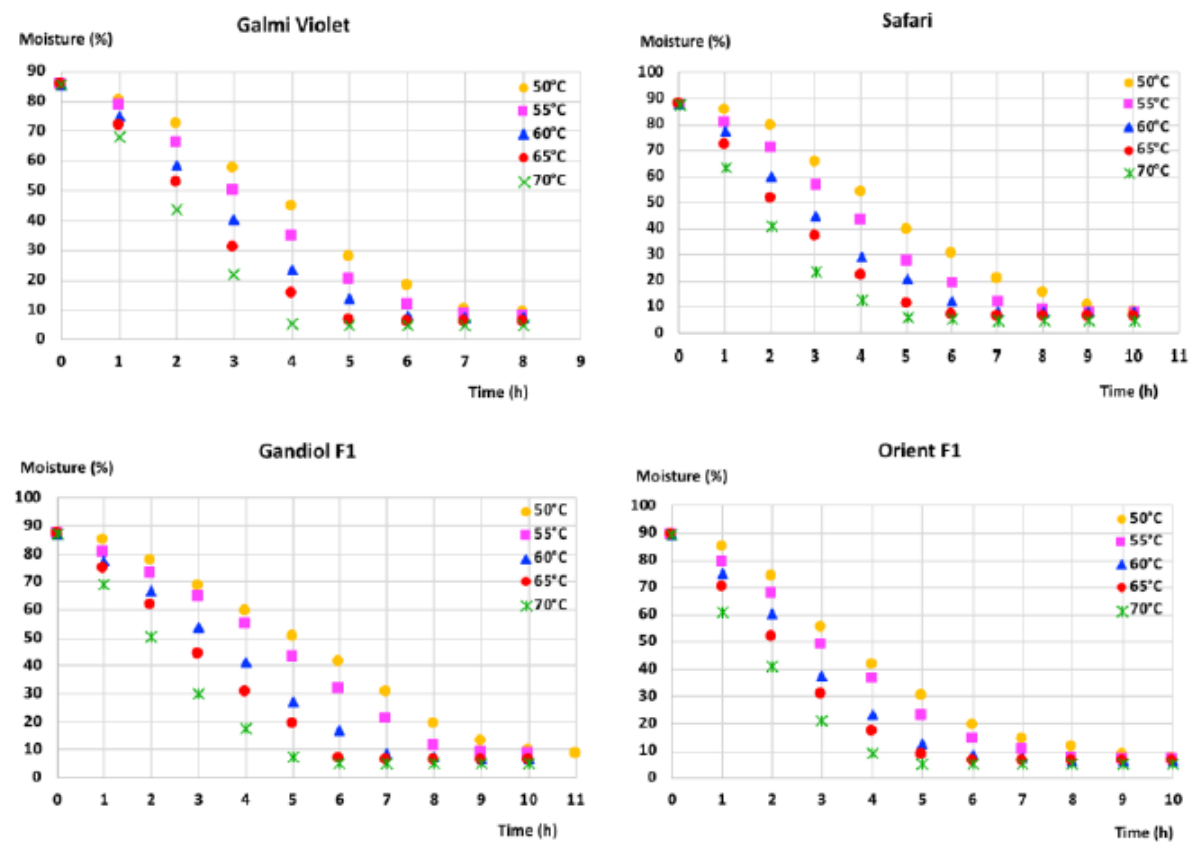

Figure 3. Evolution of moisture content of oven-dried onion varieties at different temperatures

The optimal drying time in the oven, which makes it possible to reach the stability moisture, changes inversely with the increase in temperature. Over the temperature range between $50^{\circ} \mathrm{C}$ and $70^{\circ} \mathrm{C}$, the results (Figure 3) obtained for the four varieties are as follows:

$>$ the initial moisture content of Galmi Violet $(85.56 \pm 0.60 \%)$ decreases to a moisture stability of between $8.89 \pm 0.16$ and $5.23 \pm 0.34(\%)$ for an optimal time between $8 \mathrm{H}$ and $4 \mathrm{H}$ depending on the drying temperature. At each increase in temperature $\left(+5^{\circ} \mathrm{C}\right)$, the drying time decreases $(-1 \mathrm{H})$;

$>$ with an initial moisture content of $88.11 \pm 0.61(\%)$, the stability moisture of the Safari variety, between $8.14 \pm 0.52$ and $6.30 \pm 0.26(\%)$ according to the drying temperature; is reached for an optimal time between $10 \mathrm{~h}$ and $5 \mathrm{~h}$. The drying time decreases $(-1 \mathrm{H})$ at each increase in temperature $\left(+5^{\circ} \mathrm{C}\right)$ except from $55^{\circ} \mathrm{C}$ to $60^{\circ} \mathrm{C}$ where the time step is $(-2 \mathrm{H})$;

$>$ the Gandiol F1 variety with an initial moisture content of $86.99 \pm 0.10(\%)$ has a stability moisture of between $8.68 \pm 0.33$ and $7.70 \pm 0.39(\%)$ depending on the drying temperature. The optimal drying time varies between $11 \mathrm{H}$ and $5 \mathrm{H}$ with a pitch of $(-2 \mathrm{H})$ for each increase of a step of $5^{\circ} \mathrm{C}$ in the temperature range of $50^{\circ} \mathrm{C}$ to $60^{\circ} \mathrm{C}$ and $(-1 \mathrm{H})$ for that ranging from $60^{\circ} \mathrm{C}$ to $70^{\circ} \mathrm{C}$;

$>$ for the Orient F1 variety with an initial moisture content of $89.13 \pm 0.69(\%)$, the stability moisture is between $8.54 \pm 0.41$ and $5.02 \pm 0.24(\% \mathrm{db})$ depending on the drying temperature. The optimal drying time is between $9 \mathrm{H}$ and $5 \mathrm{H}$ with a variation of $(-1 \mathrm{H})$ for each temperature increase of a step of $5^{\circ} \mathrm{C}$ in the range $50^{\circ} \mathrm{C}$ to $60^{\circ} \mathrm{C}$, of $(-2 \mathrm{H})$ in the range of $60^{\circ} \mathrm{C}$ to $65^{\circ} \mathrm{C}$ and no variation in that of $65^{\circ} \mathrm{C}$ to $70^{\circ}$ C.

For each variety, the optimal temperature and the optimal drying time are determined taking into account changes in moisture content and water activity

(Bonazzi, Dumoulin, \& Bimbenet, 2008; Charreau \& Cavaille, 1991; Jeantet, Croguennec, Schuck, \& Brulé, 2008; Jiménez Elizondo, 2011), as well as the impact of the process on polyphenols (Ali, Bordia, \& Mustafa, 1999; Lombard, Peffley, Geoffriau, Thompson, \& Herring, 2005; Yang, Meyers, van der Heide, \& Liu, 2004). These are constituents of therapeutic interest (Ali, Thomson, \& Afzal, 2000; Griffiths, Trueman, Crowther, Thomas, \& Smith, 2002; Zohri, Abdel-Gawad, \& Saber, 1995). 


\subsubsection{Optimal Drying Conditions in a Solar Greenhouse}

Figure 4 shows the evolution of the moisture content of sun-dried onion varieties at varying temperatures during drying.
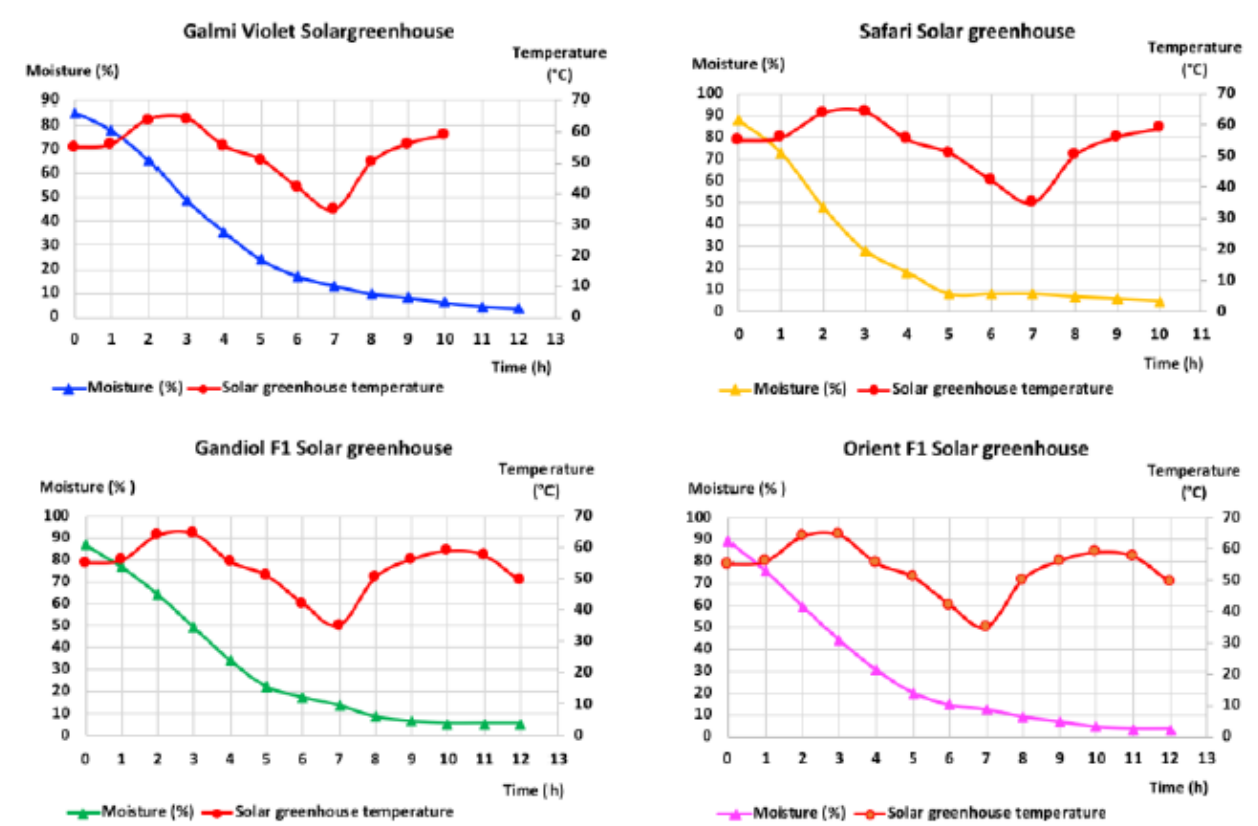

Figure 4. Evolution of the moisture content of the four sun-dried onion varieties at varying temperatures during drying

The drying of onions in a solar greenhouse unlike the oven depends on the sun. Thus during the tests the temperature and humidity in the solar greenhouse varied in the respective ranges of $35-65^{\circ} \mathrm{C}$ and $10-60 \%$. The drying kinetics of the four varieties are essentially identical.

Figure 4 shows that the stability moisture values are reached from $8 \mathrm{H}$ solar greenhouse drying and that from $10 \mathrm{H}$ the values are almost stable. Table 2 displays the different moisture contents for drying times from $8 \mathrm{H}$ to $10 \mathrm{H}$.

Table 2. Drying time in the solar greenhouse and moisture content of dried samples

\begin{tabular}{lccc}
\hline & \multicolumn{3}{c}{ Moisture (\% db) } \\
\hline & \multicolumn{3}{c}{ Drying time } \\
Variety & $8 \mathrm{H}$ & $9 \mathrm{H}$ & $10 \mathrm{H}$ \\
\hline Galmi Violet & $9.89 \pm 3.034$ & $8.23 \pm 2.004$ & $6.23 \pm 2.465$ \\
\hline Safari & $6.88 \pm 2.107$ & $5.88 \pm 0.195$ & $4.88 \pm 0.088$ \\
\hline Gandiol F1 & $8.54 \pm 2.620$ & $6.49 \pm 2.253$ & $5.45 \pm 0.954$ \\
\hline Orient F1 & $9.7 \pm 4.18$ & $6.89 \pm 1.045$ & $4.66 \pm 1.193$ \\
\hline
\end{tabular}

The moisture content is inversely proportional to the drying time in the solar greenhouse and the elimination of water is different depending on the variety. These results are compared with Aw and polyphenol values to determine the optimal drying time.

\subsection{Physico-chemical Characterization of the Samples after Drying}

Water activity (Aw), titratable acidity, and $\mathrm{pH}$ are characteristics of the environment as important in the stabilization of food products as the moisture content. To avoid any microbial activity, an Aw between 0.5 and 0.6 is necessary. Moreover, the more acidic the medium ( $\mathrm{pH}$ less than 4.5), the more it is unfavorable to chemical and biochemical degradation reactions (Bernard \& Carlier, 1992; Charreau \& Cavaille, 1991; Faiveley, 2012).

\subsubsection{Characterization of Dried Samples in an Oven}

\subsubsection{Evolution of Water Activity}

The evolution of water activity for the four varieties (Figure 5) shows that the initial Aw values between $0.940 \pm$ 
0.01 and $0.950 \pm 0.001$ decreases with increasing drying temperature. The initial Aw values are divided by a factor between 1.70 and 2.78 for each temperature step of $+5^{\circ} \mathrm{C}$ in the oven. Aw reaches values between 0.362 \pm 0.003 and $0.447 \pm 0.069$ at $60^{\circ} \mathrm{C}$. On the other hand, the Aw values of the samples for the $65^{\circ} \mathrm{C}$ and $70^{\circ} \mathrm{C}$ temperatures remain relatively stable in this range, except for the Orient F1 variety at $65^{\circ} \mathrm{C}(0.497 \pm 0.002)$.

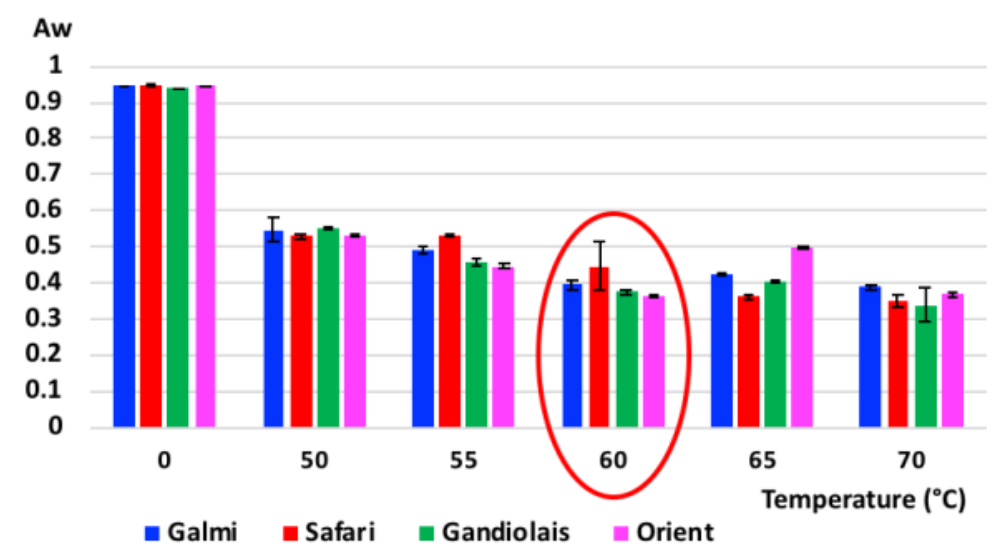

Figure 5. Water activity of the samples after optimal drying

\subsubsection{Evolution of Titratable Acidity and $\mathrm{pH}$}

The monitoring of titratable acidity and $\mathrm{pH}$ at $10 \%$ of oven-dried samples (Figure) indicates that with increasing drying temperature, the initial values of titratable acidity and $\mathrm{pH}$ at $10 \%$ ranging respectively between $4.51 \pm 0.02$ and $9.23 \pm 0.00 \mathrm{mEq} / 100 \mathrm{~g}(\mathrm{db})$ and $6.29 \pm 0.06$ and $6.42 \pm 0.03$, change inversely for the four varieties. The multiplicative factor for titratable acidity is between 0.84 and 2.53 while the $\mathrm{pH}$ is divided by a factor in the range of 1.12 to 1.28 . However, over the temperature range of $50^{\circ} \mathrm{C}$ to $70^{\circ} \mathrm{C}$, the difference is not significant for both titratable acidity and $\mathrm{pH}$ (all $\mathrm{p}$ values for Student's test are greater than 0.05 ).

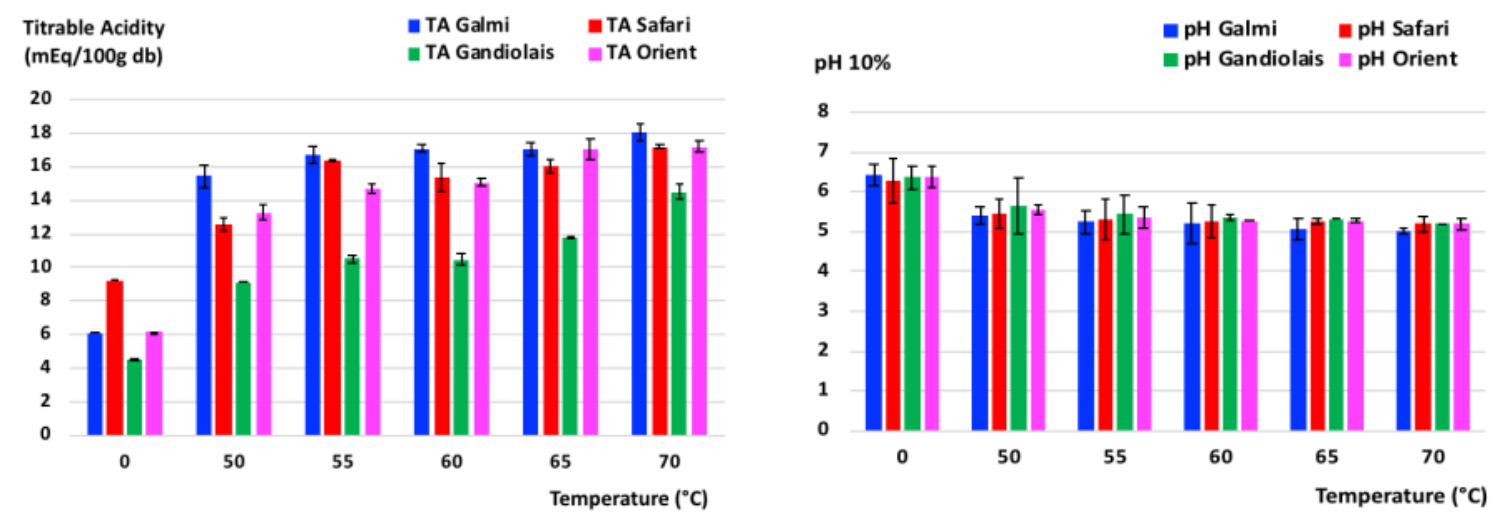

Figure 6. Titratable acidity and $\mathrm{pH}$ of the samples after drying in an oven at different temperatures

\subsubsection{Evolution of the Polyphenol Content}

The initial levels of total polyphenols (Table 1) of the four varieties, ranging from $0.111 \pm 0.0040$ to $0.312 \pm$ $0.0041 \mathrm{~g}$ EAG / 100g (db), increase with drying temperature (Figure 7Figure ). The increase in total polyphenol content is greatest at a temperature of $60^{\circ} \mathrm{C}$ with $0.546 \pm 0.0117 \mathrm{~g}$ EAG / $100 \mathrm{~g}(\mathrm{db})$ for Galmi Violet; it is 0.837 $\pm 0.0091 \mathrm{~g} \mathrm{EAG} / 100 \mathrm{~g}(\mathrm{db})$ for Safari, $0.694 \pm 0.0173 \mathrm{~g}$ EAG / $100 \mathrm{~g}(\mathrm{db})$ for Gandiol F1 and $0.691 \pm 0.0162 \mathrm{~g}$ EAG / $100 \mathrm{~g}(\mathrm{db})$ for Orient F1. This effect of temperature on polyphenol content is similar to those found in the literature (Ali et al., 1999; Lombard et al., 2005; Yang et al., 2004).

Nevertheless, from $65^{\circ} \mathrm{C}$, a decrease of about $0.3 \%$ to $37 \%$ is observed. This decrease is accentuated at $70^{\circ} \mathrm{C}$, showing the negative impact of temperature on polyphenols. 


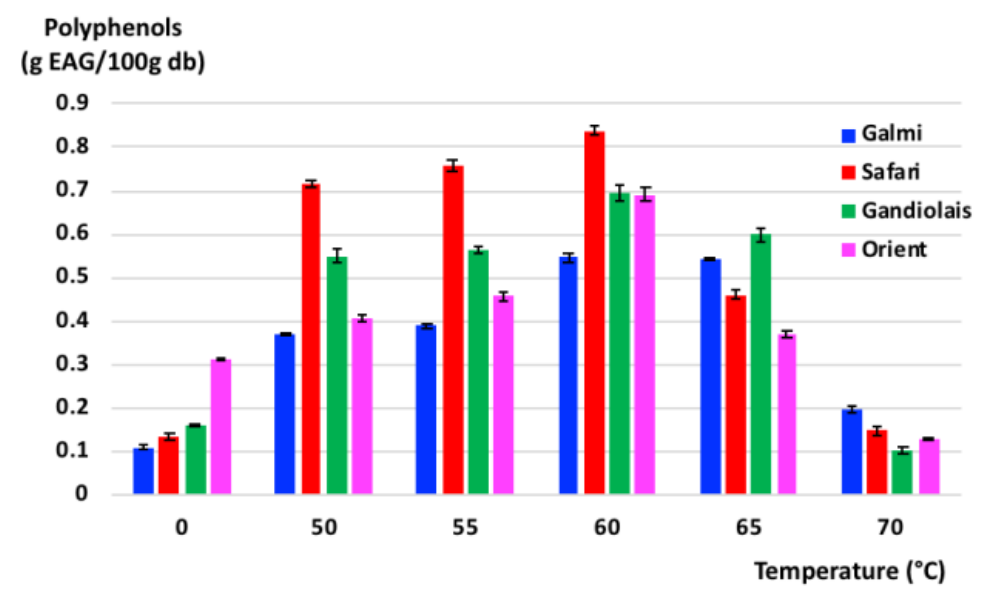

Figure 7. Polyphenol content after drying in an oven at different temperatures

The temperature range $50^{\circ} \mathrm{C}$ to $65^{\circ} \mathrm{C}$ with an optimal drying time between $6 \mathrm{H}$ and $11 \mathrm{H}$ makes it possible to obtain characteristics (Aw and moisture content) ensuring the stability of the product. However, the concern to maintain the functional properties of the polyphenols and to reduce the energy consumption makes it possible to determine the best drying time-optimal temperature pair.

Thus, the $60^{\circ} \mathrm{C}$ temperature with an optimal time of $6 \mathrm{H}$ for Galmi Violet and $7 \mathrm{H}$ for the other three varieties, is the best time/temperature pair because the polyphenol content is at its maximum. The products dried under these optimal conditions in the oven have a water activity of about 0.4 and a moisture content respectively for Galmi Violet, Orient F1, Safari and Gandiol F1 of 7.96\% $\pm 0.42 ; 7.17 \pm 0.63 ; 8.42 \% \pm 0.05$ and $8.67 \pm 0.15 \%$.

With these moisture and Aw values, the biochemical and physicochemical reactions and the development of the microorganisms responsible for the perishability of the products are then inhibited (Bernard \& Carlier, 1992; Faiveley, 2003).

\subsubsection{Characterization of Samples after Drying in a Solar Greenhouse}

In the solar greenhouse drying conditions with the respective temperature and humidity ranges in the greenhouse of $35-65^{\circ} \mathrm{C}$ and $10-60 \%$, the initial water activity of the samples decreases after $8 \mathrm{~h}$ drying (Table 1). The water activity values of the four dried onion varieties ranged from $0.577 \pm 0.007$ to $0.675 \pm 0.041$ (Table 3). These results are in the range to avoid any microbial activity (Bernard \& Carlier, 1992; Charreau \& Cavaille, 1991; Faiveley, 2012).

This decrease in the water activity of varieties continues with the increase in drying time in the solar greenhouse. Thus, for a drying time of $9 \mathrm{H}$, the values of the water activity of the samples are between $0.505 \pm 0.005$ and $0.550 \pm 0.018$ while at the end of $10 \mathrm{H}$ of drying, they are between $0.415 \pm 0.012$ and $0.491 \pm 0.006$.

Table 3. Water activity of solar greenhouse dried samples at different drying times to achieve stability moisture values

\begin{tabular}{lccc}
\hline & \multicolumn{3}{c}{ Water Activity (Aw) } \\
\hline & \multicolumn{3}{c}{ Drying time } \\
Variety & $8 \mathrm{H}$ & $9 \mathrm{H}$ & $10 \mathrm{H}$ \\
\hline Galmi Violet & $0.577 \pm 0.007$ & $0.538 \pm 0.003$ & $0.469 \pm 0.012$ \\
Safari & $0.589 \pm 0.003$ & $0.505 \pm 0.005$ & $0.477 \pm 0.000$ \\
Gandiol F1 & $0.675 \pm 0.041$ & $0.55 \pm 0.018$ & $0.415 \pm 0.012$ \\
Orient F1 & $0.617 \pm 0.008$ & $0.536 \pm 0.005$ & $0.491 \pm 0.006$ \\
\hline
\end{tabular}

The stability moisture of samples dried in a solar greenhouse at different times (Table 2) shows that the optimal drying time is $9 \mathrm{H}$ for Galmi Violet and Orient F1 varieties and $8 \mathrm{H}$ for Safari and Gandiol F1 varieties. At these optimal times, the values of the water activity (Table 3) between $0.536 \pm 0.005$ and $0.675 \pm 0.041$ ensure the absence of any microbial activity. The characteristics of the products dried under these optimal conditions are presented in Table 4. 
Table 4. $\mathrm{pH}$, titratable acidity and polyphenol content of solar greenhouse dried samples under optimal conditions

\begin{tabular}{lllll}
\hline Variety & $\begin{array}{l}\text { Optimal drying } \\
\text { time }(\mathrm{H})\end{array}$ & $\begin{array}{l}\mathrm{pH} \\
\text { (at 10\%) }\end{array}$ & $\begin{array}{l}\text { Titrable acidity } \\
(\mathrm{mEq} / 100 \mathrm{~g} \mathrm{db})\end{array}$ & $\begin{array}{l}\text { Polyphenols } \\
(\mathrm{g} / 100 \mathrm{~g} \mathrm{db})\end{array}$ \\
\hline Galmi Violet & 9 & $5.52 \pm 0.14$ & $47.43 \pm 5.035$ & $0.530 \pm 0.003$ \\
Safari & 8 & $5.56 \pm 0.03$ & $48.60 \pm 1.018$ & $0.720 \pm 0.003$ \\
Gandiol F1 & 8 & $5.35 \pm 0.03$ & $34.89 \pm 0.198$ & $0.505 \pm 0.009$ \\
Orient F1 & 9 & $5.48 \pm 0.10$ & $48.760 \pm 2.432$ & $0.607 \pm 0.005$ \\
\hline
\end{tabular}

At these optimal times of 9H for the Galmi Violet and Orient F1 varieties and 8H for the Safari and Gandiol F1 varieties, the characteristics of the solar greenhouse dried products (Table 4), compared to the initial values (Table 1), reflect that:

$>$ the titratable acidity increases with the drying temperature whereas the $\mathrm{pH}$ at $10 \%$ changes inversely for the four varieties. The titratable acidity of the varieties that are dried in solar greenhouse ranges from $34.89 \pm 0.1$ to $48.760 \pm 2.322 \mathrm{mEq} / 100 \mathrm{~g}(\mathrm{db})$. As for $\mathrm{pH}$, the values are in the range of $5.35 \pm 0.03$ to $5.56 \pm 0.03$

$>$ polyphenol contents also increase with drying. The initial values of polyphenols of Galmi Violet $(0.111$ $\pm 0.004 \mathrm{~g}$ EAG / 100g db), Safari $(0.134 \pm 0.0065 \mathrm{~g}$ EAG / 100g db) Gandiol F1 (0.162 $\pm 0.0016 \mathrm{~g}$ EAG / 100g db) and Orient F1 $(0.312 \pm 0.0041 \mathrm{~g} \mathrm{EAG} \mathrm{/} \mathrm{100g} \mathrm{db)} \mathrm{varieties} \mathrm{are} \mathrm{respectively} \mathrm{multiplied}$ by a factor of $5.48 ; 5.37 ; 3.10$ and 1.94 after drying in the optimal conditions of solar greenhouse.

Photos of onion powders obtained after drying in an oven at temperatures of $60^{\circ} \mathrm{C}, 65^{\circ} \mathrm{C}$ and $70^{\circ} \mathrm{C}$ and those obtained after drying in a solar greenhouse in $8 \mathrm{H}, 9 \mathrm{H}$ and $10 \mathrm{H}$ time are shown in the Figure 8.

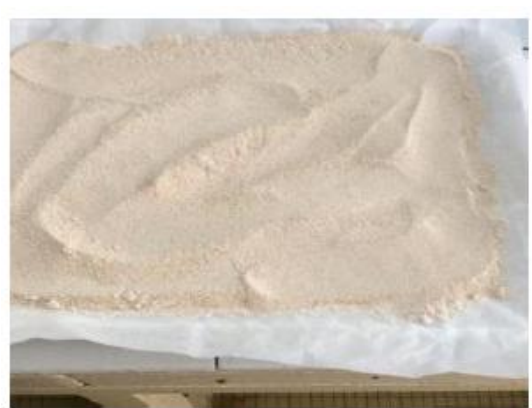

(a)

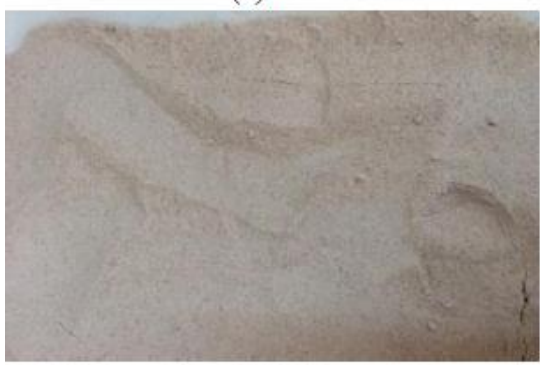

(c)

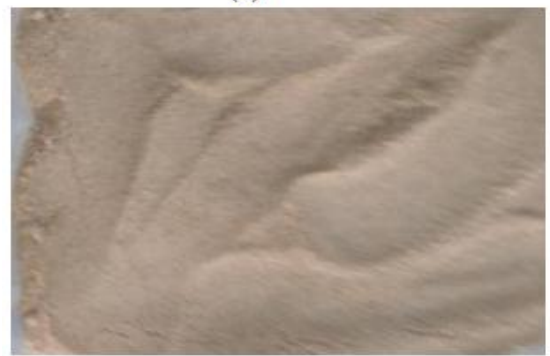

(e)

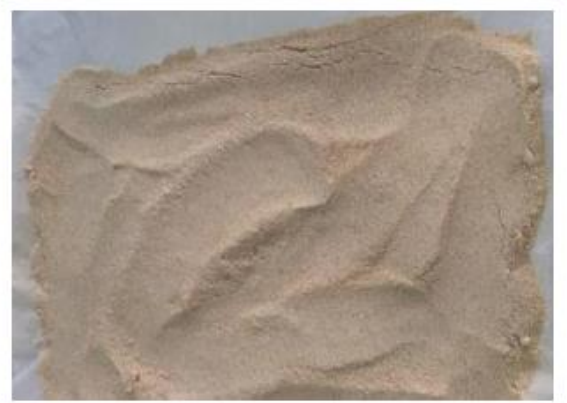

(b)

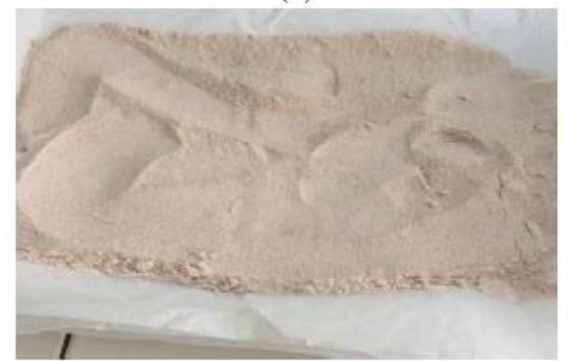

(d)

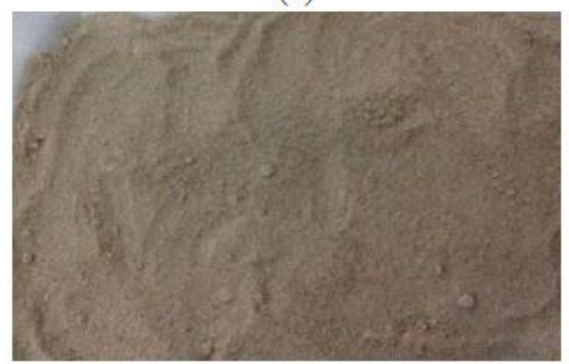

(f)

Figure 8. Onion powders obtained after drying in optimal conditions in an oven $\left[(\mathrm{a}) 60^{\circ} \mathrm{C}\right.$, (b) $65^{\circ} \mathrm{C}$ and (c) $70^{\circ}$ $\mathrm{C}]$ and solar greenhouse [(d) $8 \mathrm{H}$, (e) $9 \mathrm{H}$ and (f) $10 \mathrm{H}$ ] 
The higher the temperature and the drying time increase, the darker the color of the powders obtained is.

The impact of temperature on polyphenols (Ali et al., 1999; Lombard et al., 2005; Yang et al., 2004), constituents of therapeutic interest (Ali et al., 2000; Griffiths et al., 2002; Zohri et al., 1995), associated with the phenomenon of crusting when the removal of water is done too quickly and browning dried products (Figure 8), allow to avoid temperatures above $65^{\circ} \mathrm{C}$ and times greater than $10 \mathrm{H}$ for drying onions. On the other hand, too long exposure times consume not only a lot of energy, but can also affect the quality of the product. Therefore, the best temperature / time pairs are 55 to $65^{\circ} \mathrm{C} / 6 \mathrm{H}$ to $8 \mathrm{H}$ with an optimum at $60^{\circ} \mathrm{C}$.

As for the results obtained by drying in the greenhouse presented in Table 2, Table 3 and Table 4, they show that moisture and Aw stability are obtained without browning the products after 8 hours to 9 hours of drying with a temperature in the greenhouse varying from 35 to $65^{\circ} \mathrm{C}$ during the day. Moreover, in this solar greenhouse temperature range, the polyphenol contents of the four onion varieties increase after drying. These results are comparable to those obtained in the oven.

The results of the parametric test of Student confirm that there is no significant difference between oven drying and solar greenhouse drying kinetics under the study conditions because all $\mathrm{p}$ values are $>5 \%$.

\section{Conclusion}

The research carried out in the framework of this study made it possible to optimize the dehydration process of onion bulbs using two different energy sources. The ideal drying ranges are $55^{\circ} \mathrm{C}$ to $65^{\circ} \mathrm{C} / 6 \mathrm{H}$ to $8 \mathrm{H}$ in an oven and 35 to $65^{\circ} \mathrm{C} / 8 \mathrm{H}$ to $9 \mathrm{H}$ in a solar greenhouse to obtain products with low moisture content $(\leq 8 \%)$.

Reducing high moisture content and water activity in the onions by drying in the oven as well as in solar greenhouse thus ensures the stability of the dried products. In addition, although the drying time in solar greenhouse is greater than that in the oven, the impact of drying on the evolution of the polyphenol content is substantially identical regardless of the energy source used. These results guide the choice towards the solar source for the management of post-harvest losses through the dehydration of onions.

However, lack of control of solar greenhouse drying temperatures can affect the nutritional and organoleptic quality of dried onions. The Establishment of the desorption isotherms and the modeling of the drying kinetics is thus necessary to control the parameters and ensure the regularity of the quality of the finished product. A study of the stability of onion powders including the monitoring of the re-humidification and color changes during storage should be considered. The reconstitution of dried onions and the sensory analysis by the consumers will be the next stages to be explored for a possible vulgarization of the products.

\section{Acknowledgments}

This work was carried out at the Polytechnic school (ESP) and the Center for Food Security and Functional Molecules Studies (CESAM-RESCIF), Cheikh Anta Diop University of Dakar, Senegal. We thank them for supporting us financially and materially.

\section{References}

Agence Nationale de Statistiques et de la Démographie (ANSD). (2014). Situation Economique et Sociale du Sénégal (SES). Consulté le 2 mars 2018, à l'adresse. Retrieved from http://www.ansd.sn/index.php?option=com_sess\&view=sess\&Itemid=418

Agence de Régulation des Marchés (ARM). (2016). Rôles et Impacts des actions de l'Agence de Régulation des Marchés dans l'organisation de la sous-filière oignon au Sénégal. Agence de Régulation des Marchés.

Ahmed-Zaid, A. (1999). Optimisation des capteurs solaires plans à air: application au séchage de produits agricoles et de la pêche ( $\mathrm{PhD}$ Thesis). Valenciennes.

Albitar, N., Mounir, S., Besombes, C., \& Allaf, K. (2011). Improving the Drying of Onion Using the Instant Controlled Pressure Drop Technology. Drying Technology, 29(9), 993-1001. https://doi.org/10.1080/07373937.2010.507912

Ali, M., Bordia, T., \& Mustafa, T. (1999). Effect of raw versus boiled aqueous extract of garlic and onion on platelet aggregation. Prostaglandins, Leukotrienes and Essential Fatty Acids (PLEFA), 60(1), 43-47. https://doi.org/10.1054/plef.1998.0006

Ali, M., Thomson, M., \& Afzal, M. (2000). Garlic and onions: their effect on eicosanoid metabolism and its clinical relevance. Prostaglandins, Leukotrienes and Essential Fatty Acids (PLEFA), 62(2), 55-73. https://doi.org/10.1054/plef.1999.0124

Anwar, S. I., \& Tiwari, G. N. (2001). Convective heat transfer coefficient of crops in forced convection 
drying-an experimental study. Energy conversion and management, 42(14), 1687-1698. https://doi.org/10.1016/S0196-8904(00)00160-6

Babalis, S. J., \& Belessiotis, V. G. (2004). Influence of the drying conditions on the drying constants and moisture diffusivity during the thin-layer drying of figs. Journal of food Engineering, 65(3), 449-458. https://doi.org/10.1016/j.jfoodeng.2004.02.005

Bernard, A., \& Carlier, H. (1992). Aspects nutritionnels des constituants des aliments. Influences des technologies. In Les Cahiers de l'ENS. BANA. Lavoisier Tec \& Doc

Bonazzi, C., Dumoulin, E., \& Bimbenet, J. J. (2008). Le séchage des produits alimentaires. Industrie Alimentaire Agricole, 125(03-04), 12-22

Boughali, S. (2010). Etude et optimisation du séchage solaire des Produits agro-alimentaires dans les zones Arides et désertiques ( $\mathrm{PhD}$ Thesis). Université de Batna 2

Charreau, A., \& Cavaille, R. (1991). Séchage: I. Théorie et calculs. Techniques de l'ingénieur. Génie des procédés, 2, J24080-1

Clemente, G., Frías, A., Sanjuan, N., Benedito, J., \& Mulet, A. (2011). Influence of air velocity in dehydration of potato cubes. III European Drying Conference (EuroDrying'2011), 26-28

Direction de 1'Horticulture (DH). (2015). Direction de l'Horticulture: Statistiques horticoles. Direction de l'Horticulture

DH. (2016). Direction de l'Horticulture : Statistiques horticoles. Direction de l'Horticulture.

ESA. (2004). European Spice Association (ESA) quality minima document. Bonn, Germany.

Faiveley, M. (2003). L'eau et la conservation des aliments. Notions de biochimie alimentaire et alimentation humaine. Techniques de l'Ingénieur F, 1011

Faiveley, M. (2012). L'eau et la conservation des aliments. Techniques de l'Ingénieur F, 1011(V2).

Griffiths, G., Trueman, L., Crowther, T., Thomas, B., \& Smith, B. (2002). Onions : A global benefit to health. Phytotherapy Research, 16(7), 603-615. https://doi.org/10.1002/ptr.1222

Jannot, Y. (2006). Habilitation à diriger des recherches: Du séchage des produits alimentaires tropicaux à la caractérisation thermophysique des solides. Université de Bordeaux I

Jeantet, R., Croguennec, T., Schuck, P., \& Brulé, G. (2008). Sciences des Aliments 1- Stabilisation biologique et physico-chimique. Consulté à l'adresse https://hal.archives-ouvertes.fr/hal-01454471

Jiménez Elizondo, N. (2011). Impact des opérations thermiques agroalimentaires à hautes températures sur la dégradation des anthocyanes: Caractérisation et modélisation des cinétiques réactionnelles. Montpellier SUPAGRO - Institut des Régions Chaudes

Kiranoudis, C. T., Maroulis, Z. B., \& Marinos-Kouris, D. (1992). Drying Kinetics Of Onion And Green Pepper. Drying Technology, 10(4), 995-1011. https://doi.org/10.1080/07373939208916492

Krokida, M. K., Karathanos, V. T., Maroulis, Z. B., \& Marinos-Kouris, D. (2003). Drying kinetics of some vegetables. Journal of Food engineering, 59(4), 391-403. https://doi.org/10.1016/S0260-8774(02)00498-3

Lawrence, I., \& Lin, K. (1989). A concordance correlation coefficient to evaluate reproducibility. Biometrics, 255-268

Le Meste, M., \& Chiotelli, E. (2002). Chapitre 2. Interactions entre l'eau et les autres constituants alimentaires-Rôle dans la conformation, l'état d'association, la stabilité et la fonctionnalité des molécules. In L'eau dans les aliments (Le Meste, M., Lorient, D. \& Simatos, D., eds.). Tec \& Doc Lavoisier, Paris. Lavoisier - Tec \& Doc

Lhendup, T. (2005). Technical and financial feasibility of a solar dryer in Bhutan. Energy for Sustainable Development, 9(4), 17-24. https://doi.org/10.1016/S0973-0826(08)60496-2

Lombard, K., Peffley, E., Geoffriau, E., Thompson, L., \& Herring, A. (2005). Quercetin in onion (Allium cepa L.) after heat-treatment simulating home preparation. Journal of Food Composition and Analysis, 18(6), 571-581. https://doi.org/10.1016/j.jfca.2004.03.027

Mendez Lagunas, L. (2007). L'effet des conditions variables de séchage sur la cinétique de séchage et la qualité de l'ail (PhD Thesis). Université de Laval, Québec

Sarsavadia, P. N., Sawhney, R. L., Pangavhane, D. R., \& Singh, S. P. (1999). Drying behaviour of brined onion 
slices. Journal of Food Engineering, 40(3), 219-226. https://doi.org/10.1016/S0260-8774(99)00058-8

Tom, A. (2015). Contribution au séchage solaire des produits carnés: Modélisation et réalisation d'un séchoir adapté aux pays tropicaux. (PhD Thesis). ENSAM, Paris. Consulté à l'adresse. Retrieved from http://www.theses.fr/2015ENAM0013

Yang, J., Meyers, K. J., van der Heide, J., \& Liu, R. H. (2004). Varietal Differences in Phenolic Content and Antioxidant and Antiproliferative Activities of Onions. Journal of Agricultural and Food Chemistry, 52(22), 6787-6793. https://doi.org/10.1021/jf0307144

Zohri, A.-N., Abdel-Gawad, K., \& Saber, S. (1995). Antibacterial, antidermatophytic and antitoxigenic activities of onion (Allium cepa L.) oil. Microbiological Research, 150(2), 167-172.

https://doi.org/10.1016/S0944-5013(11)80052-2

\section{Copyrights}

Copyright for this article is retained by the author(s), with first publication rights granted to the journal.

This is an open-access article distributed under the terms and conditions of the Creative Commons Attribution license (http://creativecommons.org/licenses/by/4.0/). 